Revista Brasil. Bot., V.32, n.1, p.109-116, jan.-mar. 2009

\title{
Morfoanatomia comparada e ontogênese do pericarpo de Bidens gardneri Baker e B. pilosa L. (Asteraceae) ${ }^{1}$
}

\author{
PRICILA GREYSE DOS SANTOS JULIO ${ }^{2}$ e DENISE MARIA TROMBERT OLIVEIRA ${ }^{3,4}$
}

(recebido: 29 de maio de 2008; aceito: 04 de dezembro de 2008)

\begin{abstract}
Comparative morphology, anatomy and ontogeny of the pericarp of Bidens gardneri Baker and B. pilosa L. (Asteraceae)). The present work describes the morphology, anatomy, and ontogeny of the pericarp and pappus of Bidens gardneri Baker and B. pilosa L., species of Heliantheae (Asteraceae). Both species were found to be very similar, having inferior ovaries that are bicarpel, syncarpic, and unilocular. The pericarp develops by cell elongation, without a multiplicative phase. The exocarp is uniseriate and covered by a cuticle, with multicellular tector trichomes that persist until maturity. The outer mesocarp has three layers of parenchyma cells in B. pilosa, while B. gardneri has five cell layers. The median region of the mesocarp has from four to eight layers in both species, and there are collateral vascular bundles between the median region of the mesocarp and the inner mesocarp. The endocarp is uniseriate, although it is bi- to tri-seriate in the fusion region of carpels. The deposition of phytomelanin occur between outer and median mesocarp, earlier in $B$. pilosa. A protuberance can be seen where the aristate pappus is inserted at the apex of the pericarp; the pappus is formed by three to four rigid bristles that have trichomes towards their bases. There is a small projection (the carpopodium) at the base of the fruit where it attaches to the axis of the inflorescence. At maturity, the pericarp of both species becomes dehydrated, and in $B$. pilosa the pericarp layers are more collapsed; dehydration also occurs in B. gardneri, but some cells of the exocarp and outer mesocarp remain distinct.
\end{abstract}

Key words - anatomy, development, fruit, morphology, pappus

RESUMO - (Morfoanatomia comparada e ontogênese do pericarpo de Bidens gardneri Baker e B. pilosa L. (Asteraceae)). Este trabalho descreve a morfologia, anatomia e ontogênese do pericarpo e pápus de Bidens gardneri Baker e B. pilosa L., espécies de Heliantheae (Asteraceae). Verificou-se que as duas espécies são muito similares, possuem ovário ínfero, bicarpelar, sincárpico e unilocular. O pericarpo se desenvolve a partir do alongamento das células, sem fase multiplicativa. O exocarpo é unisseriado e recoberto por cutícula; ocorrem tricomas tectores multicelulares, que persistem até a maturidade. O mesocarpo externo possui de uma a três camadas de células parenquimáticas em B. pilosa e de uma a cinco células em B. gardneri. A região mediana do mesocarpo possui de quatro a oito camadas em ambas as espécies e, entre a região mediana do mesocarpo e o mesocarpo interno, estão imersos feixes vasculares colaterais. O endocarpo é unisseriado, mas nas regiões de fusão dos carpelos, é bi a trisseriado. Ocorre deposição de fitomelanina entre o mesocarpo externo e o mediano, mais precoce em $B$. pilosa. No ápice do pericarpo, observa-se a protuberância onde se insere o pápus aristado, formado por três a quatro cerdas rígidas, que apresentam tricomas voltados para a base. Na base do fruto, ocorre uma pequena projeção, o carpopódio, onde o fruto insere-se no eixo da inflorescência. Na maturidade, o pericarpo das duas espécies é desidratado, e, em $B$. pilosa, as camadas do pericarpo ficam mais colapsadas; em B. gardneri, também ocorre a desidratação, mas algumas células do exocarpo e mesocarpo externo permanecem distintas.

Palavras-chave - anatomia, desenvolvimento, fruto, morfologia, pápus

\section{Introdução}

Também conhecida como a tribo do girassol, Heliantheae compreende 189 gêneros e aproximadamente 2.500 espécies. Os maiores gêneros são Verbesina $(300$

1. Parte da dissertação de mestrado da primeira autora, Programa de Pós-Graduação em Ciências Biológicas (Botânica) da Universidade Estadual Paulista, Botucatu.

2. UNESP, Universidade Estadual Paulista, Instituto de Biociências, Departamento de Botânica, Caixa Postal 510, 18618-000 Botucatu, SP, Brasil.

3. Universidade Federal de Minas Gerais, Instituto de Ciências Biológicas, Departamento de Botânica, Avenida Antonio Carlos, 6627, Pampulha, Caixa Postal 486, 31270-901 Belo Horizonte, MG, Brasil.

4. Autor para correspondência: dmtoliveira@icb.ufmg.br spp.), Bidens (240 spp.), Viguiera (180 spp.), Wedelia (130 spp.) e Calea (110 spp.). A maioria dos gêneros de Heliantheae é encontrada na América do Norte e do Sul e particularmente no México (Bremer 1994).

Uma característica importante nesta tribo é a presença de fitomelanina, uma substância negra, depositada no espaço intercelular entre a camada mais externa do pericarpo e a camada mediana do mesmo. Segundo Pandey \& Dhakal (2001), esta substância está relacionada à proteção da cipsela contra a predação por insetos, porém pouco se sabe sobre esta substância.

$\mathrm{O}$ gênero Bidens L. é representado por ervas anuais ou perenes, que possuem capítulos solitários ou formando inflorescências compostas do tipo corimbos ou panículas, 
radiados ou discóides; as flores do raio são femininas ou neutras, geralmente amarelas, e as flores do disco são hermafroditas ou, raramente, funcionalmente masculinas (Bremer 1994).

Bidens gardneri Baker ocorre em fisionomias campestres de cerrado, em cerrado típico e é freqüente em áreas perturbadas e bordas de cerradão. Conhecida popularmente como picão, é uma erva ereta e pouco ramificada, com cerca de um metro de altura; suas folhas são simples e alternas e apresenta flores tubulares reunidas em capítulos radiados, com flores do raio apresentando coloração que varia do laranja ao vermelho, com ovário ínfero (Durigan et al. 2004).

Bidens pilosa $\mathrm{L}$., planta conhecida como picão-preto, é uma erva anual, com caule quadrangular, atingindo até um metro de altura; possui folhas opostas-cruzadas e as flores são diminutas, amarelas e tubulosas, com pápus formado por duas a quatro cerdas, reunidas em capítulos paleáceos. Tem ciclo anual curto, com várias gerações durante o ano. Sua inflorescência é integralmente amarela e seus frutos, quando maduros, apresentam coloração enegrecida e o pápus transformado em cerdas rijas, que facilmente aderem ao pêlo dos animais e as roupas do homem que as disseminam (Aranha et al. 1988).

Dada sua ampla dispersão e colonização de diversos ambientes, $B$. pilosa é considerada uma planta invasora (Lorenzi 1984). O estudo de órgãos reprodutivos de plantas que apresentam esta característica se torna bastante oportuno, visto que pode fornecer subsídios para trabalhos que visem ao controle populacional.

O presente trabalho objetiva descrever a morfoanatomia e o desenvolvimento do pericarpo e estruturas acessórias de B. gardneri e B. pilosa, comparando-os entre si e com a literatura pertinente, buscando reconhecer padrões estruturais comuns entre as espécies.

\section{Material e métodos}

O material vegetal constou de ovários, frutos jovens e maduros, e foi coletado em áreas residuais de cerrado da região de Botucatu, São Paulo, Brasil (22 53'17' S e 48²9'84" W - Bidens pilosa) e na reserva legal da Fazenda Palmeira da Serra, em Pratânia, São Paulo, Brasil (2302'54" S e 48 31'26" W - Bidens gardneri). Parte do material coletado foi herborizado e depositado no Herbário "Irina Delanova de Gemtchujnicov" (BOTU), do Departamento de Botânica, Instituto de Biociências da Universidade Estadual Paulista (UNESP), Câmpus de Botucatu, como documento taxonômico, registrado sob os números 24.277 (B. gardneri) e 24.278 (B. pilosa), coletados por Pricila G.S. Julio.

Inicialmente, mediu-se com régua milimetrada o comprimento de 100 cipselas de cada espécie, coletadas casualmente de, ao menos, cinco indivíduos; foi apresentada a média dos valores obtidos.

Para o estudo anatômico, as amostras foram fixadas em FAA em etanol 50\% (Johansen 1940) e conservadas em álcool etílico a $70 \%$ (Jensen 1962).

Para elaboração de laminário permanente, após desidratação em série etílica e inclusão em (2-hidroxietil)metacrilato (Leica ${ }^{\circledR}$ ) segundo as instruções do fabricante, o material foi seccionado em micrótomo rotativo com espessura variando de 8-12 $\mu \mathrm{m}$, obtendo-se séries transversais e longitudinais. As secções obtidas foram coradas com azul de toluidina a 0,05\% em tampão acetato $\mathrm{pH} 4,7$ (O'Brien et al. 1964) e montadas em Entellan ${ }^{\circledR}$.

Testes histoquímicos foram realizados, sendo utilizados os seguintes corantes e reagentes: vermelho de rutênio, para identificar polissacarídeos diversos e pectinas (Jensen 1962); floroglucinol acrescido de ácido clorídrico, para evidenciar paredes lignificadas (Sass 1951); Sudan IV, para a localização de substâncias lipídicas; lugol, para a detecção de amido; cloreto férrico, para verificar a ocorrência de compostos fenólicos (Johansen 1940).

O laminário analisado foi fotografado com máquina digital Olympus C7070WZ, adaptada a microscópio Olympus BX41TF.

\section{Resultados}

As flores de Bidens gardneri e B. pilosa são dispostas em capítulos, individualmente acompanhadas por uma bráctea paleácea, que recobre o ovário (figuras 1-3). A bráctea apresenta secção transversal em "V" e epiderme com células de tamanhos variados, cubóides, de paredes finas (figura 3) e cutícula evidente e é possível observar alguns tricomas multicelulares em diferenciação; o mesofilo é composto por células parenquimáticas alongadas longitudinalmente, de tamanhos variados (figuras 1-3), entre as quais ocorrem vários feixes vasculares e canais secretores.

Ovário (figuras 1-8) - O ovário das duas espécies é ínfero (figura 1), bicarpelar, sincárpico e unilocular, e apresenta o contorno losangular em secção transversal (figuras 2, 3) devido à disposição das flores e brácteas no capítulo.

A epiderme externa do ovário é unisseriada (figuras 3-8), composta por células cubóides, justapostas, de parede delgada e núcleos evidentes (figuras 4-7); tricomas tectores multicelulares encontram-se em diferenciação (figura 6).

O mesofilo ovariano é constituído por três regiões (figuras 3,7). A mais externa é composta por uma a cinco camadas de células tendendo a isodiamétricas, de paredes delgadas, citoplasma denso e núcleos evidentes (figuras 6, 7). A região mediana do mesofilo em B. pilosa 


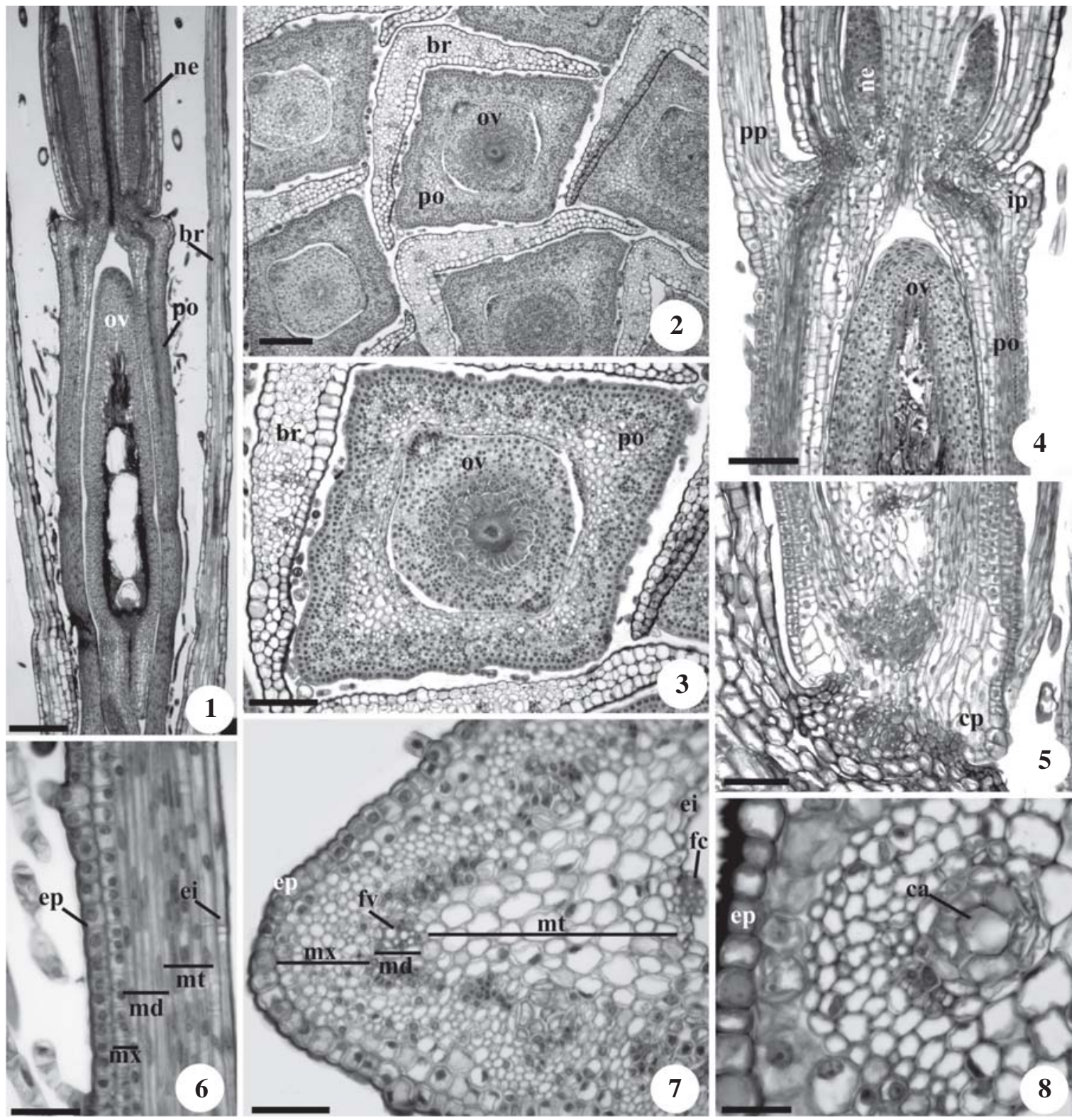

Figuras 1-8. Ovário e óvulo de Bidens gardneri (1-3, 6-8) e B. pilosa $(4,5)$. Secções longitudinais (1, 4-6). Secções transversais $(2,3,7,8)$. 1. Aspecto geral da flor. 2. Vista geral do capítulo; notar a disposição das brácteas em relação aos ovários. 3. Detalhe do ovário e óvulo. 4. Detalhe da região apical do ovário, mostrando a inserção do pápus. 5. Detalhe do carpopódio. 6, 7. Detalhes da parede ovariana, indicando as regiões do mesofilo. 8. Detalhe da região externa da parede ovariana, mostrando canal secretor. $(\mathrm{br}=$ bráctea; $\mathrm{ca}$ = canal secretor; $\mathrm{cp}$ = carpopódio; ei = epiderme interna do ovário; ep = epiderme externa do ovário; fc = região de fusão carpelar; fv = feixe vascular; ip = região de inserção do pápus; $\mathrm{md}$ = região mediana do mesofilo; $\mathrm{mt}=$ mesofilo interno; $\mathrm{mx}=$ mesofilo externo; $\mathrm{ne}=$ nectário $; \mathrm{ov}=$ óvulo; $\mathrm{po}=$ parede ovariana; $\mathrm{pp}=$ pápus $)$. Barra $=150 \mu \mathrm{m}$ (2), $125 \mu \mathrm{m}(1), 100 \mu \mathrm{m}(3-5), 50 \mu \mathrm{m}(6,7), 25 \mu \mathrm{m}(8)$.

Figures 1-8. Ovary and ovule of Bidens gardneri (1-3, 6-8) and B. pilosa $(4,5)$. Longitudinal sections (1, 4-6). Transverse sections $(2,3,7,8)$. 1 . General aspect of the flower. 2. General view of the head; note the disposal of the bracts in relation to the ovaries. 3. Detail of the ovary and ovule. 4. Detail of the apical region of the ovary, showing pappus insertion. 5. Detail of the carpopodium. 6, 7. Detail of the ovary wall, indicating the regions of the mesophyll. 8. Detail of the outer region of the ovary wall showing secretory duct. $(\mathrm{br}=$ bract; $\mathrm{ca}=$ secretory duct; $\mathrm{cp}=$ carpopodium; $\mathrm{ei}=$ inner epidermis of the ovary; $\mathrm{ep}=$ outer epidermis of the ovary; $\mathrm{fc}=$ region of carpel fusion; $\mathrm{fv}=$ vascular bundle; ip = region of pappus insertion; $\mathrm{md}=$ median region of mesophyll; $\mathrm{mt}=$ inner mesophyll; $\mathrm{mx}=$ outer mesophyll; $\mathrm{ne}=$ nectary; $\mathrm{ov}=$ ovule; $\mathrm{po}=$ ovary wall; $\mathrm{pp}=$ pappus $).$ Bar $=150 \mu \mathrm{m}$ (2), $125 \mu \mathrm{m}(1), 100 \mu \mathrm{m}(3-5), 50 \mu \mathrm{m}(6,7), 25 \mu \mathrm{m}(8)$. 
varia de cinco a sete camadas de células, enquanto em B. gardneri é constituída por quatro a oito camadas de células parenquimáticas, de formato irregular, alongadas longitudinalmente (figura 6). Na região mediana, entre o mesofilo externo e o interno, encontram-se vários feixes vasculares colaterais em início de diferenciação e quatro feixes mais diferenciados, dispostos nas regiões angulosas do ovário (figuras 3,7). Interna e paralelamente aos feixes, ocorrem canais secretores (figura 8). A camada mais interna do mesofilo é formada por três a seis camadas de células, um pouco menos alongadas longitudinalmente, em relação à região mediana do mesofilo, de lume mais largo (figuras 6,7), abrigando espaços intercelulares (figura 7), que caracterizam a formação de um parênquima frouxo.

A epiderme interna é formada por uma camada de células de tamanho e formato irregulares; na região de fusão marginal dos carpelos, a epiderme é bi a trisseriada (figura 7), com células de citoplasma denso e núcleos bastante evidentes.

Na região apical do ovário, ocorre uma protuberância revestida por epiderme unisseriada, composta por células parenquimáticas de formatos irregulares, paredes delgadas (figura 4), que constitui a região de inserção do pápus. Nesta fase, o pápus apresenta cerdas formadas em um único verticilo, ainda no início da diferenciação, compostas por células alongadas no plano longitudinal e de paredes delgadas (figura 4).

$\mathrm{Na}$ região basal do ovário, ocorre o carpopódio pouco desenvolvido (figura 5), preenchido por células parenquimáticas de amplo vacuoma; é por esta região que a flor se insere no eixo da inflorescência. Suas células têm formato irregular e paredes delgadas, sendo revestidas por células epidérmicas de maior tamanho que as que recobrem o ovário (figura 5).

Fruto jovem (figuras 9-15) - É possível observar que nenhuma das regiões do pericarpo é multiplicativa, não se estabelecendo atividade mitótica no fruto de ambas as espécies. Ocorre um alongamento do pericarpo, resultante de expansão celular, aumentando a cavidade seminal que é, posteriormente, preenchida pelo desenvolvimento da semente.

O exocarpo é unisseriado, com células cubóides e justapostas, revestidas por cutícula evidente, com citoplasma denso e núcleo também evidente (figuras 9 , 10). Nesta fase, os tricomas estão diferenciados e é possível notar que estão posicionados acropetamente (figura 9).

O mesocarpo externo diferencia células isodiamétricas, de paredes delgadas, citoplasma muito denso e núcleos evidentes (figuras 11, 12). Na região mediana do mesocarpo, ainda é possível observar, no início desta fase os canais secretores (figura 11).

Em B. pilosa (figuras 12, 13), ocorre o início da deposição de fitomelanina, que confere a cor negra ao fruto maduro, entre a região mais externa do mesocarpo e a região mediana do mesmo. Esta deposição tem início precocemente, desde a fase pós-antese. Durante a ontogênese, ocorre a formação de um espaço esquizógeno entre o mesocarpo externo e o mediano, local onde ocorre a deposição de fitomelanina que, em B. gardneri, será acumulada mais tardiamente.

Em B. pilosa, todo o desenvolvimento do fruto é mais precoce que em $B$. gardneri. A região mediana do mesocarpo de $B$. pilosa começa a se lignificar logo no início da fase jovem (figuras 11, 12), não crescendo mais a partir daí; neste mesmo período, B. gardneri ainda não exibe sinais de lignificação e o fruto continua se alongando até o final da fase jovem. A camada mais interna é formada por parênquima frouxo cujas células têm tamanhos variáveis e vacuoma muito desenvolvido (figura 12).

O endocarpo é pouco conspícuo, só se destacando as regiões multisseriadas (figura 10). As células desta região mantêm citoplasma denso e núcleos bastante evidentes, possuindo paredes delgadas.

O pápus (figuras 14,15) já está totalmente desenvolvido e apresenta de três a quatro cerdas aristadas, de secção transversal triangular. A epiderme é unisseriada, composta por células de paredes delgadas, com células silicosas ocupando os ângulos da cerda

Figures 9-15. Young fruit of Bidens gardneri $(9,10,14)$ and Bidens pilosa $(11-13,15)$. Longitudinal sections $(9,11,13,15)$. Transverse sections $(10,12,14) .9-10$. Aspects of the young pericarp, detaching trichomes; in figure 10, observe the detail of the indicated region. 11. Detail of the pericarp showing secretory duct. 12-13. Details of the pericarp, with lignified cells in the median region; note the beginning of phytomelanin deposition (asterisk). 14. Detail of the pappus with triangular transverse section, showing the presence of silicified cell (arrow) in the three angles. 15. Detail of the pappus; note the silicified cell constituting a hook form trichome (seta). $(\mathrm{ca}=$ secretory duct; $\mathrm{cs}=$ seed chamber; $\mathrm{ex}=\mathrm{exocarp}$; $\mathrm{fv}=\mathrm{vascular}$ bundle; me = outer mesocarp; $\mathrm{mi}=$ inner mesocarp; $\mathrm{mm}=$ median mesocarp; pe = pericarp; $\mathrm{se}=\mathrm{seed}$; $\mathrm{tr}=\mathrm{trichome})$. Bar = $100 \mu \mathrm{m}(11,12), 75 \mu \mathrm{m}(10,13), 50 \mu \mathrm{m}(9,15), 25 \mu \mathrm{m}(14)$. 

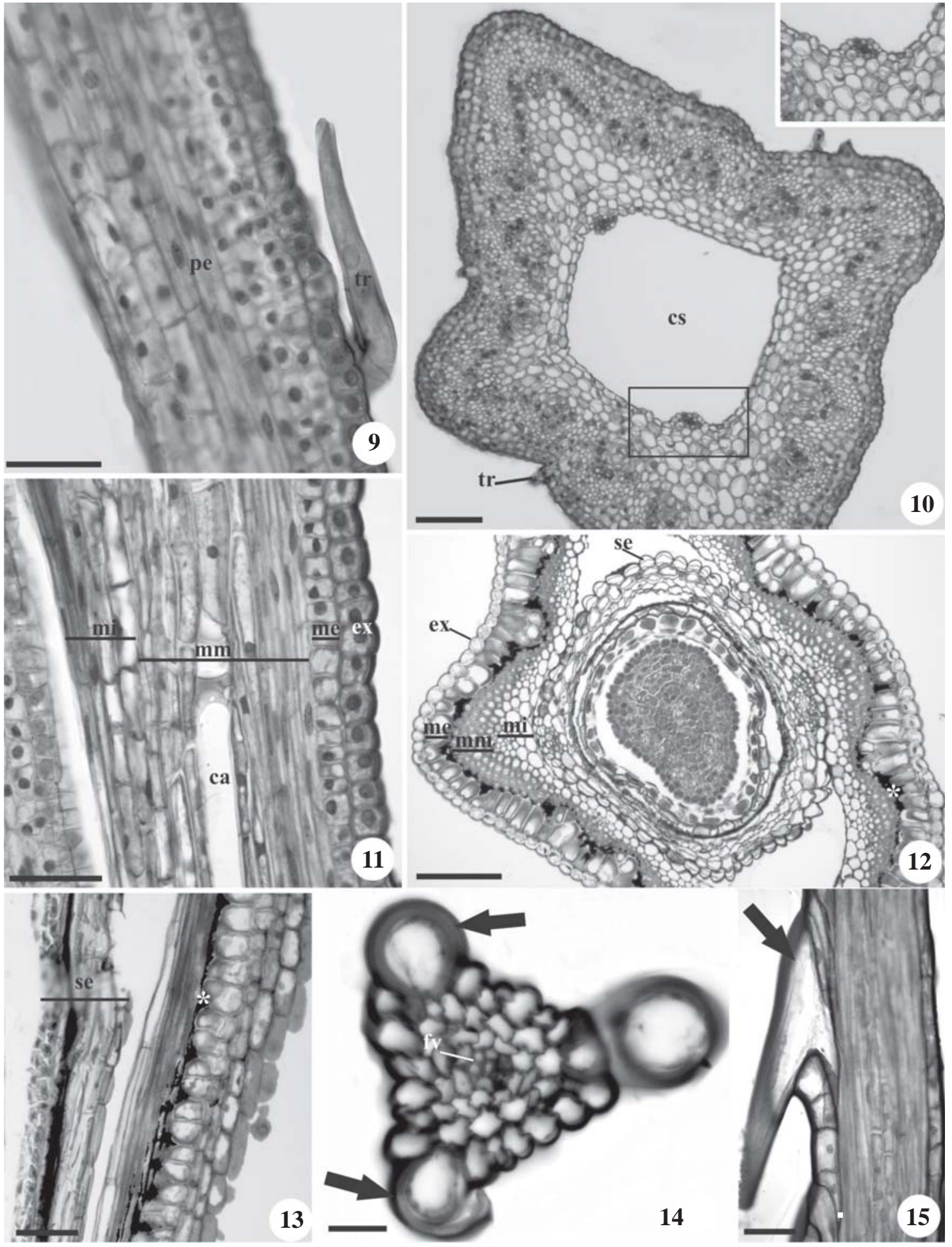

Figuras 9-15. Fruto jovem de Bidens gardneri $(9,10,14)$ e Bidens pilosa $(11-13,15)$. Secções longitudinais $(9,11,13,15)$. Secções transversais $(10,12,14) .9-10$. Aspectos do pericarpo jovem, destacando tricomas; na figura 10, observar o detalhe da região indicada. 11. Detalhe do pericarpo, mostrando canal secretor. 12-13. Detalhes do pericarpo, já com a região mediana lignificada; notar o início da deposição de fitomelanina (asterisco). 14. Detalhe do pápus com secção transversal triangular, mostrando a presença de célula silicosa (seta) nos três ângulos. 15. Detalhe do pápus; notar que a célula silicosa constitui tricoma em formato de gancho (seta). (ca = canal secretor; $\mathrm{cs}=$ cavidade seminal; ex = exocarpo; $\mathrm{fv}=$ feixe vascular; $\mathrm{me}=$ mesocarpo externo $; \mathrm{mi}=$ mesocarpo interno $; \mathrm{mm}=$ mesocarpo mediano; $\mathrm{pe}=$ pericarpo; $\mathrm{se}=$ semente $; \mathrm{tr}=\operatorname{tricoma})$. Barra $=100 \mu \mathrm{m}(11,12), 75 \mu \mathrm{m}(10,13), 50 \mu \mathrm{m}(9,15), 25 \mu \mathrm{m}(14)$. 


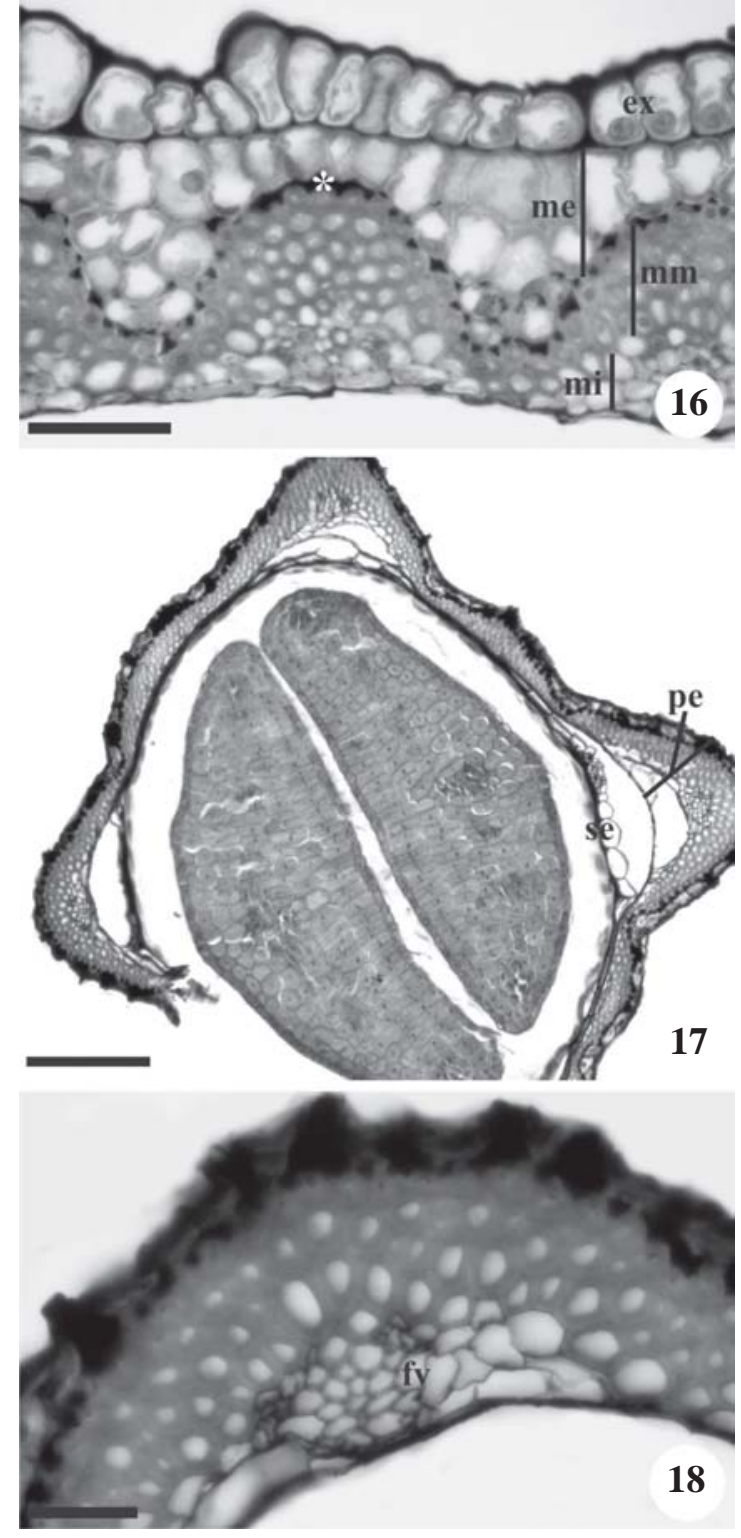

Figuras 16-18. Fruto maduro de Bidens gardneri (16) e Bidens pilosa $(17,18)$. Secção longitudinal (16). Secções transversais $(17,18)$. 16. Detalhe do pericarpo (asterisco: depósito de fitomelanina). 17. Aspecto geral do pericarpo maduro. 18. Detalhe do pericarpo, mostrando feixe vascular. (ex = exocarpo; $\mathrm{fv}=$ feixe vascular; $\mathrm{me}=$ mesocarpo externo; $\mathrm{mi}=$ mesocarpo interno; $\mathrm{mm}=$ mesocarpo mediano; pe = pericarpo; se = semente). Barra $=150 \mu \mathrm{m}$ (17), $50 \mu \mathrm{m}$ (16), $25 \mu \mathrm{m}$ (18).

Figures 16-18. Mature fruit of Bidens gardneri (16) and Bidens pilosa $(17,18)$. Longitudinal section (16). Transverse sections $(17,18)$. 16. Detail of the pericarp (asterisk: phytomelanin deposition). 17. General aspect of the mature pericarp. 18. Detail of the pericarp, showing vascular bundle. (ex = exocarp; fv = vascular bundle; $m e=$ outer mesocarp; $\mathrm{mi}=$ inner mesocarp $; \mathrm{mm}=$ median mesocarp; $\mathrm{pe}=$ pericarp; se $=$ seed). Bar $=150 \mu \mathrm{m}(17), 50 \mu \mathrm{m}(16), 25 \mu \mathrm{m}$ (18). (figura 14), formando tricomas basípetos em forma de gancho (figura 15). Internamente ocorre parênquima fundamental com um único feixe vascular no centro (figura 14).

O carpopódio não apresenta modificações nesta fase.

Maturação do pericarpo (figuras 16-18) - Durante esta fase, o pericarpo passa por intensa desidratação, que resulta no colapso de muitas células, mais reconhecível em $B$. pilosa. Próximo à dispersão, o fruto apresenta comprimento médio de $1 \mathrm{~cm}$ em $B$. pilosa e $1,5 \mathrm{~cm}$ em B. gardneri.

Em B. gardneri, é no início da maturação que ocorre lignificação da região mediana do mesocarpo, acompanhada pela deposição de fitomelanina entre a camada mais externa do mesocarpo e a camada mediana (figura 16), menos abundante que a já verificada em B. pilosa. Mesmo em frutos dispersados, podem-se distinguir todas as camadas pericárpicas, embora com células de aspecto inativo em função da desidratação.

Bidens pilosa, cuja lignificação da camada mediana do mesocarpo e depósito de fitomelanina ocorreu desde a fase jovem, agora apresenta intensa desidratação do pericarpo (figuras 17, 18). Em frutos dispersados, observa-se completo colapso do exocarpo e mesocarpo externo, cujas paredes residuais justapõem-se à camada de fitomelanina, resultando na coloração escura do fruto; o mesocarpo interno também se encontra bastante colapsado, distinguindo-se somente o mesocarpo mediano, com a camada de fibras e feixes vasculares (figura 18).

\section{Discussão}

As características gerais do ovário de $B$. gardneri e B. pilosa, em relação à posição, número e fusão de carpelos e número de lóculos conferem com as características descritas para a família (Bremer 1994).

Com relação à parede ovariana, as Asteraceae constituem um grupo com certa variabilidade no sistema fundamental. Nas espécies estudadas, destaca-se o reconhecimento de cinco regiões, ou seja, epiderme externa, região externa, mediana e interna do mesofilo, e epiderme interna. Autores que trabalharam com outras espécies, como as da tribo Vernonieae, descreveram apenas quatro regiões, como pode ser verificado em Vernonia anthelmintica (L.) Willd (Misra 1972) e V. brevifolia Less. e V. herbacea (Vell.) Rusby (Martins \& Oliveira 2007). Esta variação é facilmente explicável, já que, nas espécies aqui estudadas, ocorre a formação 
da camada de fitomelanina, não observada nas Vernonieae; a camada adicional na parede ovariana, preservada durante a ontogênese do pericarpo, parece estar relacionada ao depósito desta substância. Nas espécies de Bidens avaliadas, a região externa do mesofilo, assim como o mesocarpo externo, apresentam as células com maior densidade citoplasmática, respectivamente da parede ovariana e do pericarpo, indicando possível atividade secretora; estudos ultra-estruturais dessas regiões são de grande interesse para esclarecer a formação da camada de fitomelanina, que é pouco discutida na literatura.

Segundo Roth (1977), a fitomelanina é uma substância negra, caracteristicamente encontrada nos frutos de determinadas compostas, e provavelmente relacionada à proteção do pericarpo. Além de constituir uma barreira física, dificultando a predação de frutos, a camada de fitomelanina tem sido relacionada também à produção de substâncias tóxicas (Pandey \& Dhakal 2001), embora a literatura não tenha avançado neste sentido. Nem mesmo a composição química da fitomelanina está esclarecida; Hegnauer (1977) sugeriu que existe uma relação biogenética entre as fitomelaninas produzidas nos frutos de Eupatorieae, Heliantheae e Helenieae, com os invólucros de determinadas espécies da família e alguns poliacetilenos.

Atualmente, a ocorrência de fitomelanina é considerada uma sinapomorfia de Asteraceae e tem sido reconhecido um clado que reúne mais de 5.000 espécies cujas cipselas apresentam este caráter, o Phytomelanin Cypsela Clade (Panero 2007), que inclui as Heliantheae.

Um aspecto que se destaca nas Asteraceae é a frequiente ocorrência de estruturas secretoras, em função das quais muitas espécies são tidas como medicinais. Em amplo levantamento, Castro et al. (1997) relacionaram a produção de canais, cavidades, idioblastos, laticíferos, hidatódios, nectários extra-florais, tricomas e apêndices glandulares em folhas de espécies da família. Nas espécies de Bidens avaliadas, são observados canais secretores, os quais já se encontram diferenciados no ovário, aspecto que dificulta a verificação de sua origem. Somente trabalhos que analisem a ontogênese da parede ovariana poderão precisar se os canais são esquizógenos ou se houve também algum processo lítico em sua formação.

De acordo com Castro et al. (1997), existe certa afinidade entre as tribos Heliantheae e Eupatorieae, considerando-se a homogeneidade de ocorrência de algumas estruturas, como os ductos secretores e tricomas unisseriados, caracteres presentes nas duas espécies estudadas de Bidens. A afinidade entre as duas tribos também é destacada pela presença da camada de fitomelanina, característica tanto de Heliantheae quanto de Eupatorieae (Panero 2007).

Durante a ontogênese das cipselas de Bidens, chama atenção a ausência de fase proliferativa, em que mitoses poderiam ampliar as camadas celulares. Este aspecto tem se mostrado constante nas Asteraceae, família em que os frutos apresentam, em geral, pequeno crescimento em relação ao ovário que os produziu. De fato, o pericarpo não multiplicativo, encontrado nas espécies estudadas, é bastante funcional quando se considera que o fruto formado é muito leve, tanto em função do pequeno número de camadas celulares quando da desidratação e colapso de determinadas camadas na maturidade. Como a proteção, necessária à semente, é conferida pela camada de fibras, a mais espessa região mesocárpica de Bidens, $\mathrm{o}$ aspecto não multiplicativo constitui importante estratégia para a família, pois facilita o processo de dispersão epizoocórica destes frutos ao conferir leveza ao diásporo.

Falando-se em dispersão de Asteraceae, a estrutura mais relevante é o pápus, cálice modificado encontrado nas cipselas e bastante utilizado na identificação de gêneros e espécies, devido à especificidade de suas características (Murherjee \& Sarkar 2001). O pápus pode constituir uma estrutura especializada no transporte pelo vento (Pjil 1972), quando composto por cerdas longas e delgadas, muitas vezes de espessura capilar, ou pode estar adaptado a se prender superficialmente em animais, resultando em dispersão epizoocórica. Este é o caso das espécies ora estudadas, que apresentam pápus modificado, rígido e com ganchos projetados para base, que se prendem à superfície de animais, que os dispersam acidentalmente.

Com relação à distinção entre as duas espécies estudadas, o principal aspecto é a questão temporal do desenvolvimento do pericarpo. Em B. gardneri, espécie que apresenta a lignificação do mesocarpo mediano mais tardiamente, o alongamento celular é mantido até a fase próxima à maturação, enquanto a diferenciação das paredes secundárias das fibras não ocorre. Já em $B$. pilosa, a lignificação das fibras mesocárpicas medianas ocorre muito cedo, cessando precocemente o alongamento dos frutos, os quais atingem menor comprimento.

Agradecimentos - À Fapesp (Programa Biota, proc. no 00/ 12469-3), pelo auxílio financeiro; à Capes, pela bolsa de doutorado de P.G.S. Julio; ao CNPq, pela bolsa de produtividade em pesquisa de D.M.T. Oliveira; à Dra. Nádia Roque, da Universidade Federal da Bahia, pela identificação do material botânico. 


\section{Referências bibliográficas}

ARANHA, C., LEITÃO, H.F. \& YALN, C.A. 1988. Sistemática de plantas invasoras. Instituto Campineiro de Ensino Agrícola, Campinas, p.17.

BREMER, K. 1994. Asteraceae: cladistics and classification. Timber Press, Portland.

CASTRO, M.M., LEITÃO-FILHO, H.F. \& MONTEIRO, W.R. 1997. Utilização de estruturas secretoras na identificação dos gêneros de Asteraceae de uma vegetação do cerrado. Revista Brasileira de Botânica 20:163-174.

DURIGAN, G., BAITELLO, J.B., FRANCO, G.A.D.C. \& SIQUEIRA, M.F. 2004. Plantas do cerrado paulista: imagens de uma paisagem ameaçada. Páginas e Letras Editora e Gráfica, São Paulo.

HEGNAUER, R. 1977. The chemistry of the Compositae. In The biology and chemistry of the Compositae (V.H. Heywood, J.B. Harborne \& B.L. Turner, eds.). Academic Press, London. p.283-335.

JENSEN, W.A. 1962. Botanical histochemistry: principles and pratice. W.H. Freeman, San Francisco.

JOHANSEN, D.A. 1940. Plant microtechnique. McGrawHill Book, New York.

LORENZI, H. 1984. Considerações sobre plantas daninhas no plantio direto. In Plantio direto no Brasil (V.P. Torrado \& A.R. Raphael, eds.). Fundação Cargill, Campinas. p.13-46.
MARTINS, M.A. \& OLIVEIRA, D.M.T. 2007. Morfoanatomia comparada do fruto de Vernonia brevifolia Less. e V. herbacea (Vell.) Rusby (Asteraceae) em desenvolvimento. Revista Brasileira de Botânica 30: 101-112.

MISRA, S. 1972. Floral morphology of the Compositae: IV - tribe Vernonieae - Vernonia anthelmintica. Tokyo Botanical Magazine 85:187-199.

MURHERJEE, S.K. \& SARKAR, A.K. 2001. Morphological diversity of pappus in the subfamily Asteroideae (Asteraceae). Journal of Economic and Taxonomic Botany Additional Series 19:275-295.

O'BRIEN, T.P., FEDER, N. \& MCCULLY, M.E. 1964. Polychromatic staining of plant cell walls by toluidine blue O. Protoplasma 59:368-373.

PANDEY, A.K. \& DHAKAL, M.R. 2001. Phytomelanin in Compositae. Current Science 80:933-940.

PANERO, J.L. 2007. Compositae: key to the tribes of the Heliantheae Alliance. In Families in genera of vascular plants. Vol. VIII. Flowering Plants, Eudicots, Asterales (J.W. Kadereit \& C. Jeffrey, eds.). Springer Verlag, Berlin. p.391-395.

PIJL, L. VAN DER. 1972. Principles of dispersal in higher plants. $2^{\text {rd }}$ ed. Springer Verlag, New York.

ROTH, I. 1977. Fruits of angiosperms. Gebrüder Borntraeger, Berlin.

SASS, J.E. 1951. Botanical microtechnique. Iowa State University, Ames. 